\title{
Cage size affects dissolved oxygen distribution in salmon aquaculture
}

\author{
Tina Oldham ${ }^{1, *}$, Frode Oppedal ${ }^{2}$, Tim Dempster ${ }^{3}$ \\ ${ }^{1}$ Aquatic Animal Health Group, Institute for Marine and Antarctic Studies, University of Tasmania, Launceston, \\ Tasmania 7250, Australia \\ ${ }^{2}$ Institute of Marine Research, Matredal 5984, Norway \\ ${ }^{3}$ Sustainable Aquaculture Laboratory - Temperate and Tropical (SALTT), School of BioSciences, University of Melbourne, \\ Victoria 3010, Australia
}

\begin{abstract}
Atlantic salmon aquaculture is shifting toward larger cages, but the water quality implications of this shift are unknown. While larger cages could improve profitability through economies of scale, they may increase the risk of low dissolved $\mathrm{O}_{2}$ (DO) conditions due to reduced water exchange. Low DO conditions reduce feed intake, meaning that the benefits of shifting to larger cages must be weighed against potential negative impacts on fish growth. To test the impact of cage size on DO distribution, we recorded DO saturation in several circular cages of 2 different sizes on a commercial salmon farm: 6 with $168 \mathrm{~m}$ and 4 with $240 \mathrm{~m}$ circumference. Static strings of DO loggers at 1 , $4.5,8,12$ and $16 \mathrm{~m}$ depths recorded DO saturation once every $60 \mathrm{~s}$ throughout a $10 \mathrm{~d}$ period in midsummer. Overall, DO levels in standard $168 \mathrm{~m}$ circumference cages were suitable for salmon feeding and growth. DO levels were highly variable (57 to $134 \%$ saturation), and were lower in cages than at the reference site. On average, DO saturation decreased with depth, and was lowest during the early morning hours. Lowest DO measurements occurred in the large $240 \mathrm{~m}$ circumference cages, where 1 in 20 of all recordings were at levels known to reduce salmon feeding and growth. DO levels in larger cages can suit salmon production, but site-specific environmental conditions throughout the year must be considered to ensure there is sufficient capacity to tolerate reduced water exchange.
\end{abstract}

KEY WORDS: Hypoxia $\cdot$ Salmo salar $\cdot$ Tasmania $\cdot$ Welfare $\cdot$ Feeding $\cdot$ Environment

\section{INTRODUCTION}

In fish, all activities including locomotion, digestion, reproduction and growth, are powered by aerobic metabolism and rely on the availability of dissolved $\mathrm{O}_{2}$ (DO) (Fry 1971). As DO saturation declines and oxygen becomes metabolically limiting, activities non-essential to immediate survival, including feeding and growth, are minimized (Burt et al. 2013, Remen et al. 2016). For healthy Atlantic salmon, moderate DO levels, as high as $77 \%$ saturation, lead to reduced feed intake (Remen et al. 2016). Saturations below $40 \%$ force the switch to anaerobic metabolism, and can be lethal if conditions do not rapidly improve (Remen et al. 2016). As a result, the survival and production performance of farmed salmon is intrinsically linked to DO.

\footnotetext{
${ }^{*}$ Corresponding author: tina.oldham@utas.edu.au
}

As the largest single aquaculture commodity by value, salmonids represent $16.6 \%$ of world trade, with demand for Atlantic salmon steadily increasing (FAO 2016). To maintain growth and meet demand, technological advancements which improve efficiency and sustainability are required (Diana et al. 2013). Most cages used in salmon aquaculture are 'gravity' type cages: weighted nets suspended in the water column beneath a surface collar (Klebert et al. 2015). Average cage size has grown steadily since the inception of the salmon industry in the 1970s. Both cage diameters and depths have increased, allowing an expansion in production volumes from small 500-2000 $\mathrm{m}^{3}$ units (Huguenin \& Ansuini 1978, Huguenin 1997) to $20000-80000 \mathrm{~m}^{3}$ today (Fredheim \& Langan 2009). Plans to expand salmon farming into offshore and exposed areas will further increase pro-

() The authors 2018. Open Access under Creative Commons by Attribution Licence. Use, distribution and reproduction are unrestricted. Authors and original publication must be credited. 
duction volumes, as evidenced by the deployment of the world's largest single fish cage of $250000 \mathrm{~m}^{3}$ in 2017 (SalMar 2016). However, though larger aquaculture cages are more cost effective due to economies of scale, and are structurally better able to withstand harsh offshore conditions, increased cage size should decrease DO conditions within cages.

As cage size increases, the surface area to volume ratio of the cage declines and water exchange is reduced (Klebert et al. 2013). Aure et al. (2009) created a simple model to estimate DO levels within aquaculture cages as a function of stocking density, cage size and current speed. The model predicts that at a stocking density of $15 \mathrm{~kg} \mathrm{~m}^{-3}$ and current speed of $6 \mathrm{~cm} \mathrm{~s}^{-1}$, DO concentrations would drop from $90 \%$ of ambient levels within a cage $30 \mathrm{~m}$ across to $50 \%$ in a cage $60 \mathrm{~m}$ across. Predicted DO levels drop further with increased stocking density or cage length, and decreased current speed (Aure et al. 2009).

Poor DO conditions, below levels known to cause reduced feed consumption and in some cases even death, have been documented in standard commercial salmon cages (12500 to $24500 \mathrm{~m}^{3}$ ) on 3 continents (Bergheim et al. 2006, Johansson et al. 2007, Burt et al. 2012, Stehfest et al. 2017). For this reason, any alterations to production strategy which may increase the likelihood of poor DO conditions, such as increasing cage size, should be approached with caution.

While the theoretical constraints and consequences of larger cages for DO levels are clear, the effect of cage size on DO has never been tested in a full-scale industrial setting. Using a unique site where 2 different cage sizes (168 and $240 \mathrm{~m}$ circumference) were co-located and contained commercial densities of salmon, we tested if DO saturation differed with cage size.

\section{MATERIALS AND METHODS}

\section{Experimental setup}

The experimental period ran from 14 to 24 December 2015 on a commercial Atlantic salmon farm in south-east Tasmania's Huon estuary $\left(43.26^{\circ} \mathrm{S}\right.$, $\left.147.07^{\circ} \mathrm{E}\right)$. Bottom depth beneath the cages ranged from 18 to $30 \mathrm{~m}$. Ten cages were evenly spaced in 2 parallel rows of 5 cages with approximately $100 \mathrm{~m}$

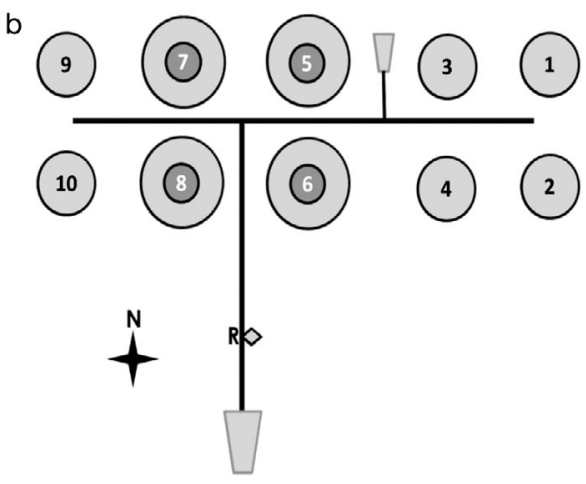

Fig. 1. (a) Geographic location of the farm site in south-eastern Tasmania, Australia. (b) Cage layout and orientation at the study site. Standard $68 \mathrm{~m}$ circumference cages $(1,2,3,4,9,10)$ are represented by solid cir, whereas large $240 \mathrm{~m}$ circumference cages $(5,6,7,8)$ are circles with ark centres. The reference site $200 \mathrm{~m}$ south of the cages (diamond, R) (c) Diagram of the doubleetted cage and location of dissolved $\mathrm{O}_{2}$ loggers which were positioned midway between the edge and centre on the western side of each cage

between all cages, arranged perpendicular to the primary N-S direction of tidal current flow (Fig. 1a,b). Each cage had 2 nets, an internal fish-containment net (mesh size: $35 \mathrm{~mm}$ ) as well as an external predator net (mesh size: $125 \mathrm{~mm}$ ).

Six of the cages were 'standard' size 168 m circumference circular tubes with internal nets measuring $52.5 \mathrm{~m}$ in diameter $\times 16.5 \mathrm{~m}$ deep $\left(\sim 35000 \mathrm{~m}^{3}\right.$ volume), while 4 of the cages were 'large' 240 m circumference circular tubes with internal nets measuring $76 \mathrm{~m}$ in diameter $\times 23 \mathrm{~m}$ deep $\left(\sim 104000 \mathrm{~m}^{3}\right.$ volume) . The farm's standard anti-fouling maintenance program, whereby the nets of all cages are visually monitored and regularly cleared of biofouling, was followed throughout the study. Visual inspection performed by divers and remotely operated vehicles determined that no detectable blockage increase occurred on any cages below the top metre of netting at any point throughout the study. Stocking densities ranged from 2.11 to $4.04 \mathrm{~kg} \mathrm{~m}^{-3}$, and average fish weight was between 2.27 and $3.18 \mathrm{~kg}$ based on data supplied by the farm (Table 1). Fish weight was determined during well-boat transfer of the full cage population at the time of cage stocking. As fish had 
Table 1. Cage position (Fig. 1), cage size, and weight (mean $\pm \mathrm{SD}$ ) and stocking density of Atlantic salmon in each cage

\begin{tabular}{|cccc|}
\hline $\begin{array}{c}\text { Cage } \\
\text { position }\end{array}$ & $\begin{array}{c}\text { Cage } \\
\text { size }\end{array}$ & $\begin{array}{c}\text { Fish weight } \\
(\mathrm{kg})\end{array}$ & $\begin{array}{c}\text { Stocking density } \\
\left(\mathrm{kg} \mathrm{m}^{3}\right)\end{array}$ \\
\hline 1 & Standard & $3.18 \pm 0.06$ & 3.8 \\
2 & Standard & $3.11 \pm 0.05$ & 3.9 \\
3 & Standard & $3.05 \pm 0.06$ & 4.0 \\
4 & Standard & $3.06 \pm 0.07$ & 4.0 \\
5 & Large & $2.57 \pm 0.04$ & 2.3 \\
6 & Large & $2.80 \pm 0.06$ & 2.6 \\
7 & Large & $2.27 \pm 0.05$ & 2.1 \\
8 & Large & $2.91 \pm 0.06$ & 2.6 \\
9 & Standard & $3.07 \pm 0.03$ & 3.9 \\
10 & Standard & $3.07 \pm 0.03$ & 3.9 \\
\hline
\end{tabular}

been recently distributed among cages at the beginning of the trial, there were minor size and density variations between cages with mean fish weights and stocking densities lower in the large cages than in the standard cages (Table 1). Fish were fed to satiation twice daily, beginning at 06:00 and 16:00 h.

We recorded DO in all 10 cages and a reference site $200 \mathrm{~m}$ south of the nearest cage. Static strings of DO loggers with copper anti-fouling caps (RBRsoloDO, RBR) were deployed at $1,4.5,8$ and $12 \mathrm{~m}$ in all cages, with an extra logger at $16 \mathrm{~m}$ in the large cages and at the reference site (Fig. 1c). DO saturation measurements were recorded once every $60 \mathrm{~s}$, by each logger, throughout the $10 \mathrm{~d}$ period. Across all 45 loggers, a total of 739958 DO measurements were collected. Temperature profiles from 1 to $16 \mathrm{~m}$ depth were collected from the reference site at the beginning and end of the study on 16 and 27 December 2015, respectively.

\section{Data analyses}

To test for differences in DO conditions between treatments (standard and large cages), we created a linear mixed effects model using the 'nlme' package (Pinheiro et al. 2016) in R environment version 3.2.0 (www.r-project.org). The model used DO saturation as the dependent variable, fixed effects of treatment and depth, and random effects of time nested within cage. Contour plots of DO conditions through time were created for each individual cage as well as the reference site in Surfer v.10 via kriging interpolation.

To assess the implications of observed DO levels, DO measurements were compared against previously determined critical physiological thresholds for Atlantic salmon. For each treatment (standard, large, reference), the proportion of all DO measurements collected which fell below the critical production thresholds of limiting oxygen saturation (LOS) and reduced feed intake were calculated. Briefly, the LOS is considered a lower extreme for fish welfare and corresponds to the DO level below which an individual can no longer regulate its metabolic rate, and if exceeded can lead to death (Claireaux \& Chabot 2016). Similarly, feed intake is generally stable with declining DO until a temperature-dependent threshold is reached, below which feeding declines. Because both the LOS and reduced feed intake thresholds are temperature dependent, the values used for this analysis were based on the locally collected temperature profiles. Using the findings of Remen et al. $(2013$, 2016) for healthy, uninfected fish, feed intake was estimated to decline below $76 \%$ saturation, with an LOS of $47 \%$ saturation. DO saturations greater than $76 \%$ were deemed suitable for salmon growth and welfare. These benchmark levels are conservatively low, as fish in general in southeastern Tasmanian waters, and specifically during this study, were infected with amoebic gill disease which likely increases the susceptibility of fish to low DO levels (Fisk et al. 2002, Oldham et al. 2016).

\section{RESULTS}

DO saturations were highly variable throughout the study (Fig. 2) and ranged from 57 to $118 \%$ in cages and 69 to $134 \%$ at the reference site. The water column was well mixed from 0 to $16 \mathrm{~m}$ depth with regards to temperature and ranged from 15.3 to $15.5^{\circ} \mathrm{C}$ at the beginning of the trial and 16.9 to $17.1^{\circ} \mathrm{C}$ at the end. On average, DO was higher at the reference site $(96 \pm 0.03 \%)$ than in either the standard $(90 \pm 0.02 \%)$ or large $(89 \pm 0.03 \%)$ cages (mean $\pm \mathrm{SE}$ ) . There was a small, but significant difference between mean DO saturation in the large and standard cages $(p=0.037)$, but no difference between positions among cages of the same size

DO saturation decreased with depth in both cage sizes $(p<0.0001)$, but not at the reference site (Table 2$)$. The lowest average DO saturation, $82 \pm 5 \%$, occurred at the $16 \mathrm{~m}$ depth in the large cages, as compared to $95 \pm 5 \%$ at the $16 \mathrm{~m}$ depth of the reference site (mean $\pm \mathrm{SD}$ ). Of the $10 \mathrm{~d}$ included in the study, lowest mean daily DO occurred on 19 December 2015, which corresponded with a neap tide, when water flow was lowest (Fig. 3). DO levels also varied with time of day (Fig. 4). Similar patterns were recorded in both the cages and at the reference site, where DO saturations increased throughout daylight 


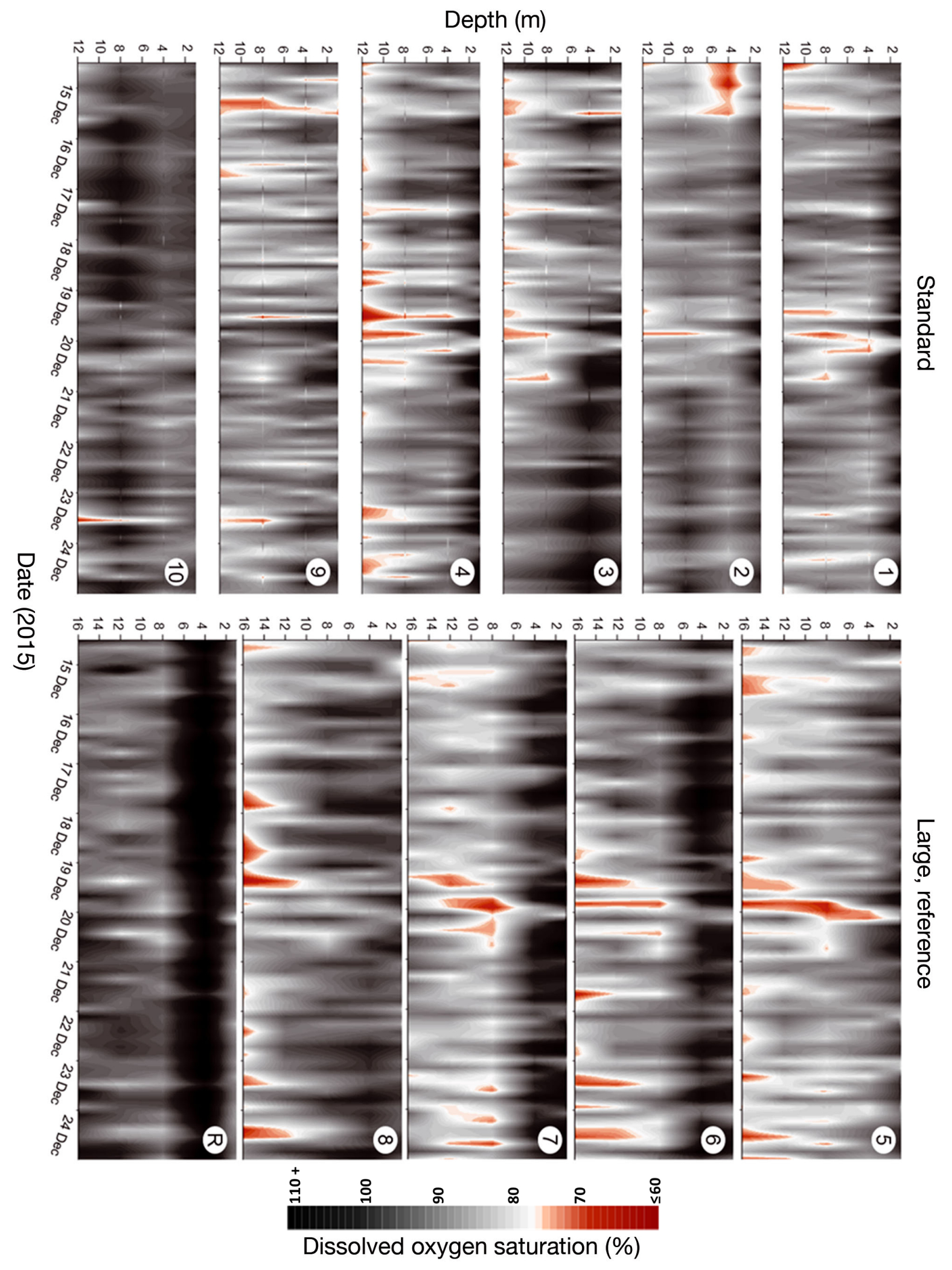

Fig. 2. Dissolved $\mathrm{O}_{2}$ saturation in each cage and at the reference site throughout the trial from 14 to 24 December 2015 . Low dissolved $\mathrm{O}_{2}$ levels known to reduce feed intake and growth in post-smolt Atlantic salmon (Remen et al. 2016) are shaded in red. Numbers in the upper right corner of plots correspond to cage numbers in Fig. $1 \mathrm{~b}$ 
Table 2. Mean $\pm \mathrm{SD}$ of recorded dissolved $\mathrm{O}_{2}$ saturations across the depth profile in each cage size and at the reference site

\begin{tabular}{|lccr|}
\hline Depth $(\mathrm{m})$ & Standard & Large & Reference \\
\hline 1 & $95.1 \pm 4.7$ & $97.4 \pm 5.1$ & $90.4 \pm 3.9$ \\
4.5 & $90.2 \pm 4.3$ & $95.8 \pm 4.8$ & $111.4 \pm 4.4$ \\
8 & $89.5 \pm 4.6$ & $86.4 \pm 5.0$ & $91.7 \pm 4.4$ \\
12 & $85.2 \pm 4.2$ & $85.5 \pm 5.5$ & $92.8 \pm 5.9$ \\
16 & NA & $81.9 \pm 5.2$ & $94.8 \pm 5.1$ \\
\hline
\end{tabular}

hours to a peak in the afternoon, after which they dropped through the night to a minimum in the early morning (Fig. 4).

The majority of DO measurements collected during this trial were physiologically suitable for Atlantic salmon post-smolt growth and welfare (Fig. 5). No measurements were recorded below the LOS for Atlantic salmon post-smolts as calculated by Remen et al. (2013). Further, all measurements at the reference site were above the level known to reduce feed intake, and less than $1 \%$ of measurements in the standard sized cages were below it. In the large cages, $5 \%$ of all DO measurements were below the level known to reduce feed intake. There was a clear pattern with depth in the percentage of measurements that were below the reduced feed intake threshold: 1 and $4.5 \mathrm{~m}$ always had suitable DO conditions, whereas $8(3 \%), 12(5 \%)$ and $16 \mathrm{~m}(15 \%)$ had increasingly poor DO levels (Figs. $2 \& 5$ ).

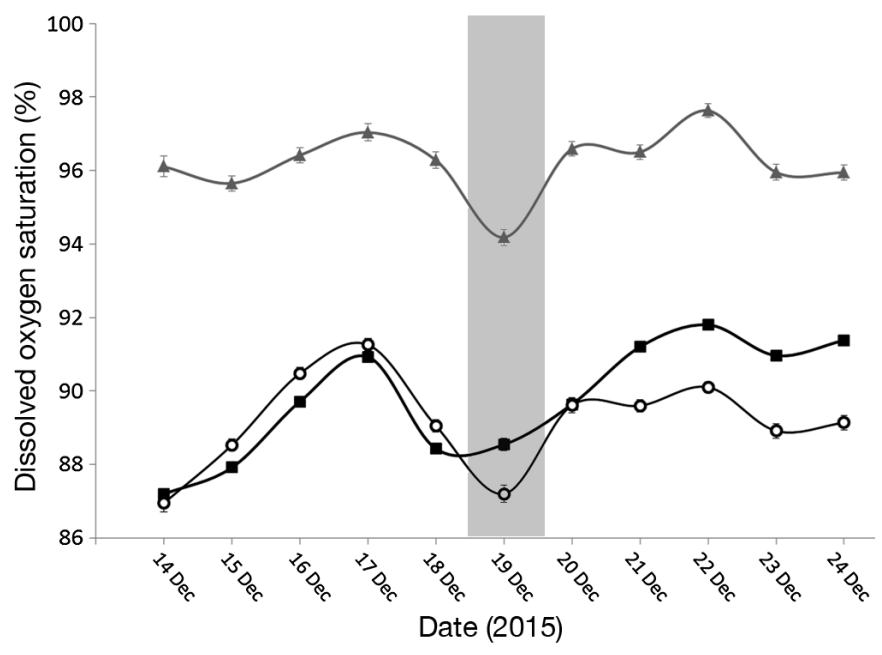

Fig. 3. Mean daily dissolved $\mathrm{O}_{2}$ saturation in each cage type and at the reference site. $(\Delta)$ Reference conditions, $(\square)$ standard cages and (O) large cages. Error bars represent $95 \%$ confidence intervals. The grey shaded area in the centre of the plot denotes a neap tidal cycle

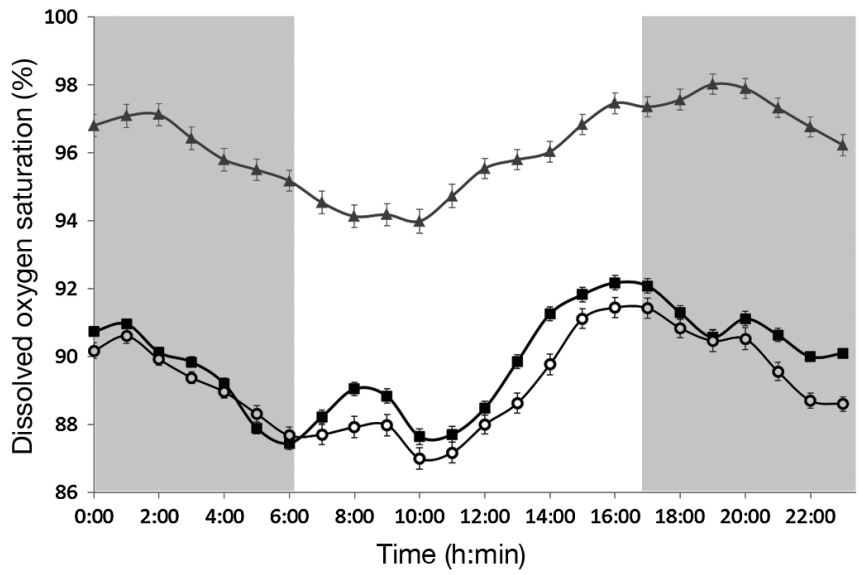

Fig. 4. Mean hourly dissolved $\mathrm{O}_{2}$ saturation in each cage type and at the reference site. $(\Delta)$ Reference conditions, $(\square)$ standard cages and (O) large cages. Error bars represent 95\% confidence intervals. The grey shading denotes periods of darkness, while the unshaded area denotes daylight hours

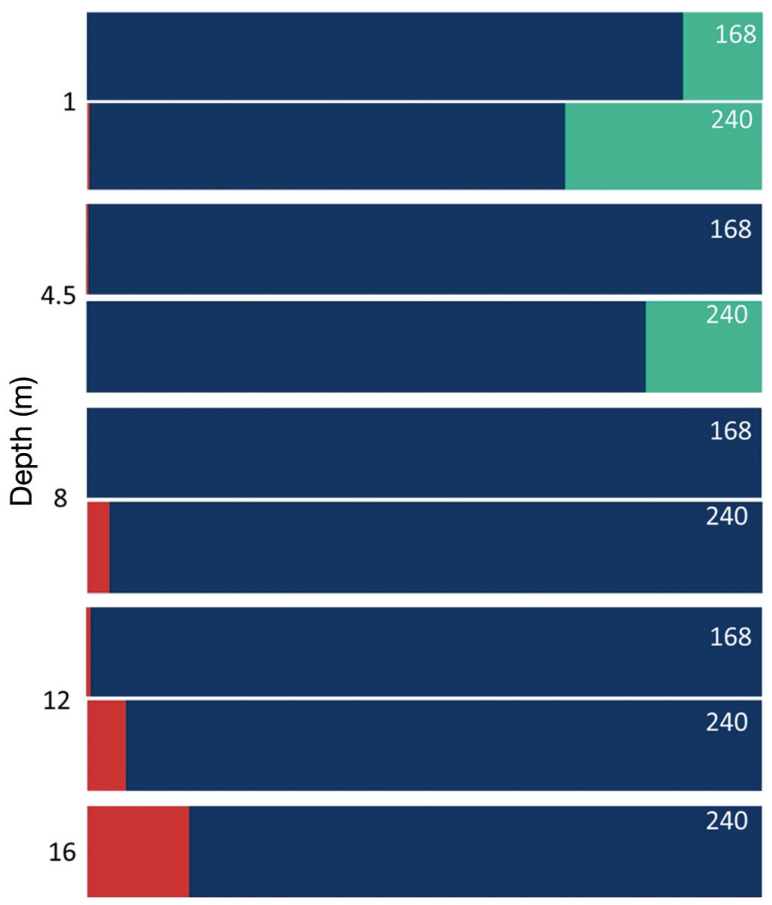

Fig. 5. Proportions of collected dissolved $\mathrm{O}_{2}$ measurements which fall within identified production thresholds: below dissolved $\mathrm{O}_{2}$ of maximum feed intake (red), within ideal conditions (blue) and super-oxygenated (green). The number in the upper right corner denotes cage size (circumference in $\mathrm{m}$ ), and numbers on the left side identify measurement depth (m)

\section{DISCUSSION}

As one of the primary determinants of fish metabolism, understanding DO dynamics in aquaculture cages is critical for maximizing production perform- 
ance (Fry 1971). Our study provides evidence that DO levels are lower in larger cages, but also demonstrates that DO concerns need not prohibit the use of larger cages as long as ambient environmental conditions are sufficient to tolerate the reduced water exchange. Further, the continuous, high-resolution DO dataset presented here provides new insights as to the distribution and variability of DO in salmon cages, and highlights key parameters for consideration when developing monitoring protocols.

Our study was conducted at full industrial scale, with stocking densities at the lower end $\left(\leq 4 \mathrm{~kg} \mathrm{~m}^{-3}\right)$ of the range for modern production (up to $25 \mathrm{~kg} \mathrm{~m}^{-3}$ ). While mean DO saturation only differed marginally between cage sizes, $90 \pm 0.02 \%$ (standard) and $89 \pm$ $0.03 \%$ (large), there were considerable differences at the lower extremes. Though $99 \%$ of all DO measurements in the standard cages were at levels suitable for salmon production, almost 1 in 6 of the measurements at $16 \mathrm{~m}$ depth in the large cages were at levels known to reduce feed intake and growth in healthy fish (Figs. 2 \& 5), despite stocking densities being lower than or equivalent to those in the standard cages. The observed pattern of decreasing DO saturation with increasing depth could explain the lower DO in large cages, as they extended deeper than the standard cages, but this pattern was only present in cages and not at the reference site (Table 2).

It has been well established that fish do not distribute themselves evenly throughout cages, but rather alter their distribution and behaviour in response to a wide variety of factors (Oppedal et al. 2011a). While some studies have observed avoidance of extremely poor DO conditions (Johansson et al. 2007, Stehfest et al. 2017), evidence suggests that other environmental factors, such as temperature and light, override behavioural avoidance of moderate DO levels known to reduce feed intake and growth (Johansson et al. 2006, Oldham et al. 2017, Solstorm et al. 2018). Such uneven distribution can result in intense crowding and observed fish densities as much as $20 \times$ the stocking density (Oppedal et al. 2011b). These findings suggest that the low DO measurements in the large cages are not simply a result of the cages being deeper, but also the result of altered fish distribution and/or the larger cage structure impeding water exchange. How fish utilize space in different size cages and the impact of cage size on water exchange specifically, are topics that warrant further investigation. Understanding the drivers behind sub-optimal DO conditions would allow targeted mitigation measures, such as the addition of supplemental oxygenation at the depths and times of greatest concern, or the use of lights to optimize the distribution of fish biomass throughout the cage, to be implemented effectively (Endo et al. 2008, Wright et al. 2015).

Despite the lower DO levels in large cages, the majority of measurements collected during this study in both cage sizes were at levels suitable for Atlantic salmon production performance and welfare (Figs. 2 \& 5). Overall, DO levels displayed a high degree of temporal and spatial variability, ranging from 57 to $134 \%$ saturation, and were similar to conditions observed in previous studies (Johansson et al. 2006, 2007, Burt et al. 2012). Spatially, we observed a consistent pattern of decreasing DO saturation with increasing depth inside cages (Table 2). This pattern is similar to conditions observed by Johansson et al. (2006) on a research farm, but the opposite to that observed on commercial farms in both Norway and Canada (Johansson et al. 2007, Burt et al. 2012). Although no universal mechanism driving DO distribution in aquaculture cages can be pinpointed due to the many complex interacting forces present, what is evident from these studies spanning 3 continents is that sitespecific patterns exist. At each site, considerations such as differing oxygen solubility with temperature, altered mixing patterns as a result of density gradients, and the specific controlling factors affecting current velocity, direction and regularity must all be considered in order to understand prevailing DO conditions (Johansson et al. 2007, Burt et al. 2012).

Throughout this study, we also observed a high degree of temporal variability, with DO saturation fluctuating both on daily and hourly timescales. Daily mean DO saturation ranged from 87 to $92 \%$ in cages and from 94 to $97 \%$ at the reference site. DO levels at the reference site were less variable, but followed the same daily trends as DO levels in cages (Fig. 3). Lowest daily mean DO in both cage sizes and at the reference site occurred on 19 December 2015, which coincided with a neap tide. Neap tides, which occur just after the 1st or 3rd quarters of the moon, are when there is the least difference between high and low water, and thus minimal water movement. A previous study which investigated the relationships between DO, current velocity and tide predictions found a significant correlation between current velocities and DO conditions in salmon cages, but no relationship with local tide predictions (Johansson et al. 2007). A major difference between their study sites and that of this trial, however, is that water currents in the Huon estuary are primarily tide driven whereas at their fjordal sites, current patterns are 
more complex (CSIRO 2000, Johansson et al. 2007). Given the importance of tides in controlling currents at our study site, it is logical that neap tides would coincide with lower DO conditions.

We also observed a distinct daily pattern to DO fluctuations. Broadly, DO levels increased through the daylight hours to a peak in the afternoon (16:00 to $19: 00 \mathrm{~h}$ ), and decreased throughout the night to a minimum in the early morning $(6: 00$ to $10: 00 \mathrm{~h}$, Fig. 4). The pattern was most pronounced at the reference site, but conditions in both cage sizes also followed the same pattern. While we do not have data to confirm this explanation, a likely possibility is that photosynthesis by algae during daylight hours causes a daily increase in DO saturation, and drawdown due to respiration without replacement at night creates a daily minimum (Wildish et al. 1993). Although the precise pattern we observed in this trial is likely to be specific to farms in the Huon estuary, the influence of daylight on DO conditions in cages has important implications for farms considering site placements in high latitude areas that experience light intensities too low for primary production during large periods of the year.

Failure to account for local DO conditions can result in reduced feed intake and growth, increased susceptibility to disease and, in extreme cases, mortality (Remen et al. 2012, 2013, 2014, 2016, Burt et al. 2013). Our results confirm the expectation that DO levels are lower in larger cages, but also demonstrate that larger cage sizes can be used without impacting salmon production performance or welfare when ambient DO conditions are sufficient, such as those recorded throughout this study. However, in locations with lower rates of DO replenishment, such as the conditions observed by Stehfest et al. (2017) in Macquarie Harbour, Tasmania, shifting to larger cages is not recommended. Even in this study, with low stocking densities and high replenishment rates, limiting DO conditions occurred in the large cages. Therefore, use of very large cages, such as Ocean Farm 1, or higher stocking densities in the large cages studied here, present risks for salmon welfare and production performance even at sites with high DO replenishment (SalMar 2016). Further, though the precise patterns documented here of decreasing DO with depth and during the night may be site specific, they could have parallels in many marine cage aquaculture situations. Together, this study illustrates the importance of site- and time-specific considerations when developing monitoring protocols or considering alterations to production strategy, such as larger cages.
Acknowledgements. The authors thank the personnel at Huon Aquaculture and Fletcher Warren-Myers, Daniel William Wright, Francisca Samsing, Michael Sievers, Cassandra Pert, Juan Manuel Valero Rodriguez, Matthew Le Feuvre and Kris Oldham for their hard work and assistance in the field. Funding for this work was provided by an Australian Research Council Future Fellowship grant to T.P., the Norwegian Research Council 'Future Welfare' project (267800), Huon Aquaculture Company and an Australian Government Research Training Program Scholarship awarded to T.O.

\section{LITERATURE CITED}

Aure J, Vigen J, Oppedal F (2009) Hva bestemmer vannutskiftning og oksygenforhold i oppdrettsmerder? Kyst og Havbruk 2009, Havforskningsinstituttet, Bergen, p 169-171

Bergheim A, Gausen M, Næss A, Hølland PM, Krogedal P, Crampton V (2006) A newly developed oxygen injection system for cage farms. Aquacult Eng 34:40-46

* Burt K, Hamoutene D, Mabrouk G, Lang C and others (2012) Environmental conditions and occurrence of hypoxia within production cages of Atlantic salmon on the south coast of Newfoundland. Aquacult Res 43:607-620

Burt K, Hamoutene D, Perez-Casanova J, Kurt Gamperl A, Volkoff H (2013) The effect of intermittent hypoxia on growth, appetite and some aspects of the immune response of Atlantic salmon (Salmo salar). Aquacult Res 45:124-137

Claireaux G, Chabot D (2016) Responses by fishes to environmental hypoxia: integration through Fry's concept of aerobic metabolic scope. J Fish Biol 88:232-251

CSIRO (2000) Huon Estuary Study—environmental research for integrated catchment management and aquaculture. Final report to Fisheries Research and Development Corporation. Project number 96/284, June 2000. CSIRO Division of Marine Research Marine Laboratories, Hobart

* Diana JS, Egna HS, Chopin T, Peterson MS and others (2013) Responsible aquaculture in 2050: valuing local conditions and human innovations will be key to success. Bioscience 63:255-262

Endo A, Srithongouthai S, Nashiki H, Teshiba I, Iwasaki T, Hama D, Tsutsumi H (2008) DO-increasing effects of a microscopic bubble generating system in a fish farm. Mar Pollut Bull 57:78-85

FAO (Food and Agriculture Organization of the United Nations) (2016) The state of world fisheries and aquaculture 2016. Contributing to food security and nutrition for all. FAO, Rome

Fisk D, Powell M, Nowak B (2002) The effect of amoebic gill disease and hypoxia on survival and metabolic rate of Atlantic salmon (Salmo salar). Bull Eur Assoc Fish Pathol 22:190-194

Fredheim A, Langan R (2009) Advances in technology for off-shore and open ocean finfish aquaculture. In: Burnell G, Allan G (eds) New technologies in aquaculture: Improving production efficiency, quality and environmental management. Woodhead Publishing, Cambridge, p 914-944

Fry F (1971) 1 - The effect of environmental factors on the physiology of fish. Fish Physiol 6:1-98

*Huguenin JE (1997) The design, operations and economics of cage culture systems. Aquacult Eng 16:167-203

*Huguenin JE, Ansuini FJ (1978) A review of the technology 
and economics of marine fish cage systems. Aquaculture 15:151-170

Johansson D, Ruohonen K, Kiessling A, Oppedal F, Stiansen JE, Kelly M, Juell JE (2006) Effect of environmental factors on swimming depth preferences of Atlantic salmon (Salmo salar L.) and temporal and spatial variations in oxygen levels in sea cages at a fjord site. Aquaculture 254:594-605

Johansson D, Juell JE, Oppedal F, Stiansen JE, Ruohonen K (2007) The influence of the pycnocline and cage resistance on current flow, oxygen flux and swimming behaviour of Atlantic salmon (Salmo salar L.) in production cages. Aquaculture 265:271-287

Klebert P, Lader P, Gansel L, Oppedal F (2013) Hydrodynamic interactions on net panel and aquaculture fish cages: a review. Ocean Eng 58:260-274

Klebert P, Patursson O, Endresen PC, Rundtop P, Birkevold J, Rasmussen HW (2015) Three-dimensional deformation of a large circular flexible sea cage in high currents: field experiment and modeling. Ocean Eng 104:511-520

Oldham T, Rodger H, Nowak BF (2016) Incidence and distribution of amoebic gill disease (AGD) - an epidemiological review. Aquaculture 457:35-42

Oldham T, Dempster T, Fosse JO, Oppedal F (2017) Oxygen gradients affect behaviour of caged Atlantic salmon Salmo salar. Aquacult Environ Interact 9:145-153

K Oppedal F, Dempster T, Stien LH (2011a) Environmental drivers of Atlantic salmon behaviour in sea-cages: a review. Aquaculture 311:1-18

Oppedal F, Vågseth T, Dempster T, Juell JE, Johansson D (2011b) Fluctuating sea-cage environments modify the effects of stocking densities on production and welfare parameters of Atlantic salmon (Salmo salar L.). Aquaculture 315:361-368

Pinheiro J, Bates D, DebRoy S, Sarkar D, R Core Team (2016) nlme: Linear and nonlinear mixed effects models R package version 3.1-128. https://CRAN.R-project.org/package $=$ nlme

Editorial responsibility: Pablo Sánchez Jerez, Alicante, Spain
Remen M, Oppedal F, Torgersen T, Imsland AK, Olsen RE (2012) Effects of cyclic environmental hypoxia on physiology and feed intake of post-smolt Atlantic salmon: initial responses and acclimation. Aquaculture 326-329: 148-155

Remen M, Oppedal F, Imsland AK, Olsen RE, Torgersen T (2013) Hypoxia tolerance thresholds for post-smolt Atlantic salmon: dependency of temperature and hypoxia acclimation. Aquaculture 416-417:41-47

* Remen M, Aas TS, Vågseth T, Torgersen T, Olsen RE, Imsland A, Oppedal F (2014) Production performance of Atlantic salmon (Salmo salar L.) postsmolts in cyclic hypoxia, and following compensatory growth. Aquacult Res 45:1355-1366

* Remen M, Sievers M, Torgersen T, Oppedal F (2016) The oxygen threshold for maximal feed intake of Atlantic salmon post-smolts is highly temperature-dependent. Aquaculture 464:582-592

SalMar (2016) SalMar annual report 2015. SalMAr, Kverva, www.salmar.no/en/annual-reports

Solstorm D, Oldham T, Solstorm F, Klebert P, Stien LH, Vågseth T, Oppedal F (2018) Dissolved oxygen variability in a commercial sea-cage exposes farmed Atlantic salmon to growth limiting conditions. Aquaculture 486: 122-129

Stehfest KM, Carter CG, McAllister JD, Ross JD, Semmens JM (2017) Response of Atlantic salmon Salmo salar to temperature and dissolved oxygen extremes established using animal-borne environmental sensors. Sci Rep 7: 4545

Wildish D, Keizer P, Wilson A, Martin J (1993) Seasonal changes of dissolved oxygen and plant nutrients in seawater near salmonid net pens in the macrotidal Bay of Fundy. Can J Fish Aquat Sci 50:303-311

*Wright DW, Glaropoulos A, Solstorm D, Stien LH, Oppedal F (2015) Atlantic salmon Salmo salar instantaneously follow vertical light movements in sea cages. Aquacult Environ Interact 7:61-65

Submitted: October 26, 2017; Accepted: February 19, 2018 Proofs received from author(s): April 5, 2018 